\title{
Alcohol-Related Morbidity and Mortality
}

\author{
Jürgen Rehm, Ph.D., Gerhard Gmel, Ph.D., Christopher T. Sempos, Ph.D., And \\ Maurizio Trevisan, M.D., M.S.
}

\begin{abstract}
Alcohol use is related to a wide variety of negative health outcomes including morbidity, mortality, and disability. Research on alcohol-related morbidity and mortality takes into account the varying effects of overall alcohol consumption and drinking patterns. The results from this epidemiological research indicate that alcohol use increases the risk for many chronic health consequences (e.g., diseases) and acute consequences (e.g., traffic crashes), but a certain pattern of regular light-to-moderate drinking may have beneficial effects on coronary heart disease. Several issues are relevant to the methodology of studies of alcoholrelated morbidity and mortality, including the measurement of both alcohol consumption and the outcomes studied as well as study design. Broad summary measures that reflect alcohol's possible effects on morbidity, mortality, and disability may be more useful than measures of any one outcome alone. KEY WORDS: AODR (alcohol and other drug related) mortality; morbidity; epidemiological indicators; chronic AODE (alcohol and other drug effects); acute AODE; amount of AOD use; alcoholic beverage; heart disorder; meal and meal time
\end{abstract}

A lcohol use contributes to a range of acute and chronic health consequences, from injuries resulting from traffic crashes to cancer and cardiovascular disease. Research has explored the relationships between the risk for alcoholrelated morbidity and mortality and both the overall amount of alcohol consumed and the pattern of drinking. This article will review this research, with a focus on the relationship between alcohol use and coronary heart disease (CHD).

Alcohol-related mortality is studied more frequently than alcoholrelated morbidity. More than 80 studies have examined the relationship between a person's average volume of alcohol consumption (i.e., average number of drinks per day) and alcohol-related mortality (see Rehm et al. $2001 b$ for a meta-analysis of studies conducted through 1999). Research has linked varying average levels of alcohol consumption (i.e., light, moderate, heavy) to increased and sometimes decreased risk for morbidity and mortality related to more than 60 disease conditions (English et al. 1995; Single et al. 1999; Gutjahr et al. 2001; Ridolfo and Stevenson 2001; Rehm et al. in press $b$ ). Some of these research findings are reflected in the table accompanying this article.

Fewer studies examine alcoholrelated morbidity alone or a combination of morbidity and mortality. One study that grouped morbidity and mortality together examined the impact of alcohol on coronary heart disease (CHD)(Rehm et al. 1997); in this study, which used data from the National Health and Nutrition Examination Epidemiologic FollowUp Study, based on a large representative survey of the U.S. general population, the data did not distinguish between people newly diagnosed with
JÜRGEN REHM, PH.D., is chief executive officer and director of the Addiction Research Institute, Zurich, Switzerland; professor in the Department of Public Health Sciences, University of Toronto; and senior scientist at the Centre for Addiction and Mental Health, Toronto, Canada.

GERHARD GMEL, PH.D., is a co-director of research at the Swiss Institute for the Prevention of Alcohol and Drug Problems, Lausanne, Switzerland.

CHRISTOPHeR T. SEMPOS, PH.D., is a professor and director of graduate studies, and MAURIZIO TREVISAN, M.D., M.S., is a professor and chairman in the Department of Social and Preventive Medicine, School of Medicine and Biomedical Sciences, both at the University at Buffalo, Buffalo, New York.

This research was supported by the Swiss Federal Office of Public Health, grant 01.001510. 
CHD and people who had died of the disorder. Overall, information about alcohol-related morbidity alone is limited because studies with morbidity as the endpoint demand substantial resources to assess individual outcomes in an objective and standardized way.

Even scarcer than studies of alcoholrelated morbidity are studies of the effects of alcohol consumption on disability or quality of life (i.e., how alcohol use causes health-related activity limitations, as defined in the International Classification of Functioning, Disability and Health (World Health Organization [WHO] 2001). The lack of studies linking alcohol use to disability or quality of life is on the one hand surprising, as the first global study of alcohol-related morbidity and mortality clearly indicated that alcohol causes a larger proportion of global disability than global mortality. Specifically, it found that 1.5 percent of all deaths were attributable to alcohol, but 6 percent of all life years lost to disability were attributable to alcohol (Murray and Lopez 1996). On the other hand, even in developed countries, investigators do not collect as much data on disability as they do on mortality, because mortality is easier to quantify and data recording is required by law (i.e., a death certificate must be filled out in a standardized way) (Goerdt et al. 1996; see also Rehm and Gmel 2000). Unlike the registration of deaths, there is no routine registration of disability, which would allow relatively easy access for research purposes, linking other data such as alcohol use to disability endpoints. That is, if a disability registration existed, researchers could more easily study the link between alcohol use and disability. As a result, studies on disability are harder to conduct and require more resources. Despite these challenges, disability and quality of life have been receiving increasing attention as health outcomes, both subjectively and as part of summary measures of health (i.e., measures that integrate effects on morbidity, mortality, and disability) (Murray et al. 2000).

The following sections examine the possible chronic and acute health consequences of alcohol use, focusing on the example of CHD. This review does not examine alcohol's role in the social, legal, and financial consequences of alcohol use and alcohol-related injury, as this subject is covered elsewhere (see Rehm 20051; Klingemann and Gmel 2001; see also the article by Gmel and Rehm in this issue).

\section{Chronic Consequences of Alcohol Use}

The table gives an overview of the risks for major chronic diseases related to varying levels of alcohol consumption, based on the results of observational data from cohort and case control studies that mainly used mortality as an endpoint. Because data on morbidity alone are not sufficiently available for most disease conditions (Single et al. 1999), metaanalyses usually combine mortality and morbidity as endpoints. In cohort studies, researchers evaluate a group of people, known as a cohort, who are disease free at the beginning of the study, to assess if they have been exposed to potential risk factors. The cohort is then followed over time and monitored for the occurrence of disease endpoints and, in some studies, changes in risk factor exposure. The objective is to assess which risk factors are related to the risk of developing a disease or condition. The purpose of case control studies is to assess whether people affected by a disease (i.e., cases) are more or less likely than a comparable group of people who do not have the disease (i.e., control subjects) to have been exposed to the relevant risk factors before developing the disease (see Gordis 1999).

In the table, relative risk estimates are shown to quantify the effect size of the risk relationships. For example, females in drinking category I, who drink on average up to 20 grams of pure alcohol per day, ${ }^{1}$ have a relative risk of 1.14 , compared with female abstainers, of developing breast cancer. A relative risk of 1.14 corresponds to a 14-percent higher risk. For females drinking more than 40 grams of pure alcohol per day (drinking category III), the relative risk is 1.59 , or about one and one-half times as large as for female abstainers, and corresponds to a 59-percent risk increase.

The International Classification of Diseases (ICD) is a system for coding both nonfatal and fatal events. Under the ICD system, the medical information provided on the death certificate, for example, is coded to indicate the underlying cause of death. The table shows the ICD codes from the 9th and 10th editions of the ICD for each disease group (WHO 1977, 1992).

As shown in the table, research has demonstrated that, for many chronic diseases, the risk of disease increases with increasing average daily alcohol consumption. Most of the major disease categories listed in the table have not been linked to specific patterns of drinking. However, this may be the result of the lack of investigation into such relationships. For example, although researchers have speculated that breast cancer risk may be influenced by the frequency of heavy drinking episodes (defined as the consumption of more than five drinks on one occasion without regularly drinking this amount), no research has explored this relationship (Kohlmeier and Mendez 1997). One disease risk that is clearly affected by the pattern of alcohol consumption is the risk for cardiovascular disease (CVD), especially CHD (see below).

\section{Alcohol Consumption, Coronary Heart Disease, and Other Cardiovascular Outcomes}

Average Light-to-Moderate Drinking. The most comprehensive meta-analysis on average consumption and CHD found that this relationship was represented by a J-shaped curve (see the accompanying figure) (Corrao et al. 2000). That is, compared with abstinence from alcohol, low-to-moderate average consumption of alcohol is

\footnotetext{
${ }^{1}$ In the United States, a drink is considered to be 0.5 ounces (oz) or 15 grams of alcohol, which is equivalent to $12 \mathrm{oz}$ (355 milliliters [mL]) of beer, $5 \mathrm{oz}(148 \mathrm{~mL})$ of wine, or $1.5 \mathrm{oz}(44 \mathrm{~mL})$ of 80 -proof distilled spirits (U.S. Department of Health and Human Services [USDHHS] 2000).
} 
Relative Risk for Major Chronic Disease Categories, by Gender and Average Drinking Category

\begin{tabular}{|c|c|c|c|c|c|c|c|c|}
\hline \multirow[b]{3}{*}{ Disease } & \multirow{3}{*}{$\begin{array}{l}\text { ICD-9 } \\
\text { code }\end{array}$} & \multirow{3}{*}{$\begin{array}{l}\text { ICD-10 } \\
\text { code }\end{array}$} & \multicolumn{3}{|c|}{ Females } & \multicolumn{3}{|c|}{ Males } \\
\hline & & & \multicolumn{6}{|c|}{ Drinking Category* } \\
\hline & & & $\mathbf{I}$ & II & III & I & II & III \\
\hline Malignant neoplasms & $140-208$ & $\mathrm{C} 00-\mathrm{C} 97$ & & & & & & \\
\hline Mouth and oropharynx cancers & $140-149$ & $\mathrm{C} 00-\mathrm{C} 14$ & 1.45 & 1.85 & 5.39 & 1.45 & 1.85 & 5.39 \\
\hline Esophagus cancer & 150 & C15 & 1.80 & 2.38 & 4.36 & 1.80 & 2.38 & 4.36 \\
\hline Liver cancer & 155 & $\mathrm{C} 22$ & 1.45 & 3.03 & 3.60 & 1.45 & 3.03 & 3.60 \\
\hline $\begin{array}{l}\text { Breast cancer } \\
\text { Under } 45 \text { years of age } \\
45 \text { years and over }\end{array}$ & 174 & C50 & $\begin{array}{l}1.14 \\
1.15 \\
1.14\end{array}$ & $\begin{array}{l}1.41 \\
1.41 \\
1.38\end{array}$ & $\begin{array}{l}1.59 \\
1.46 \\
1.62\end{array}$ & & & \\
\hline Other neoplasms & $210-239$ & D00-D48 & 1.10 & 1.30 & 1.70 & 1.10 & 1.30 & 1.70 \\
\hline Diabetes mellitus & 250 & E10-E14 & 0.92 & 0.87 & 1.13 & 1.00 & 0.57 & 0.73 \\
\hline Neuropsychiatric conditions & $\begin{array}{l}290-319 \\
324-359\end{array}$ & $\begin{array}{l}\text { F01-F99, } \\
\text { G06-G98 }\end{array}$ & & & & & & \\
\hline Unipolar major depression & 300.4 & F32-F33 & RR not av & ble; $A F$ co & not be det & ined other & e (Rehm et & in press $b$ ) \\
\hline Epilepsy & 345 & G40-G41 & 1.34 & 7.22 & 7.52 & 1.23 & 7.52 & 6.83 \\
\hline Alcohol use disorders & $\begin{array}{c}291,303 \\
305.0\end{array}$ & F10 & $\begin{array}{c}\mathrm{AF}^{* *} \\
100 \% \dagger\end{array}$ & $\begin{array}{c}\mathrm{AF} \\
100 \%\end{array}$ & $\begin{array}{c}\mathrm{AF} \\
100 \%\end{array}$ & $\begin{array}{c}\mathrm{AF} \\
100 \% \\
\end{array}$ & $\begin{array}{c}\mathrm{AF} \\
100 \%\end{array}$ & $\begin{array}{c}\mathrm{AF} \\
100 \%\end{array}$ \\
\hline Cardiovascular diseases (CVD) & $390-459$ & I00-I99 & & & & & & \\
\hline Hypertensive disease & $401-405$ & I10-I13 & 1.40 & 2.00 & 2.00 & 1.40 & 2.00 & 4.10 \\
\hline Coronary heart disease & $410-414$ & I20-I25 & 0.82 & 0.83 & 1.12 & 0.82 & 0.83 & 1.00 \\
\hline Cerebrovascular disease & $430-438$ & I60-I69 & & & & & & \\
\hline Ischemic stroke & & & 0.52 & 0.64 & 1.06 & 0.94 & 1.33 & 1.65 \\
\hline Hemorrhagic stroke & & & 0.59 & 0.65 & 7.98 & 1.27 & 2.19 & 2.38 \\
\hline Other CVD causes & $\begin{array}{l}415-417,423- \\
424,426-429 \\
440-448,451- \\
459\end{array}$ & $\begin{array}{l}\text { I00, I26-I28, } \\
\text { I34-I37, I44- } \\
\text { I51, I70-I99 }\end{array}$ & 1.50 & 2.20 & 2.20 & 1.50 & 2.20 & 2.20 \\
\hline Digestive diseases & $530-579$ & K20-K92 & & & & & & \\
\hline Cirrhosis of the liver & 571 & $\mathrm{~K} 70, \mathrm{~K} 74$ & 1.26 & $9.54 \dagger$ & $9.54 \dagger$ & 1.26 & $9.54 \dagger$ & $9.54 \dagger$ \\
\hline
\end{tabular}

NOTE: Relative risk estimates are shown to quantify the effect size of the risk relationships. For example, females in drinking category I have a relative risk of 1.14 , compared with female abstainers, of breast cancer. A relative risk of 1.14 corresponds to a 14-percent higher risk. For females in drinking category III, the relative risk is 1.59 , or about one and one-half times as large as for female abstainers. The same relationship can also be expressed as a risk increase of 59 percent.

Varying numbers of studies were used to report on the different diseases. Measurement problems for outcomes affected the reliability of the data for some endpoints, especially the different subtypes of strokes and the unspecified categories such as "other cardiovascular disease" or "other neoplasms." The results for these categories should be regarded with caution.

*Definition of drinking categories:

Category I: for females, $0-19.99 \mathrm{~g}$ pure alcohol daily; for males, 0-39.99 $\mathrm{g}$ pure alcohol daily

Category II: for females, 20-39.99 g pure alcohol daily; for males, 40-59.99 g pure alcohol daily

Category III: for females, $40 \mathrm{~g}$ or more pure alcohol; for males, $60 \mathrm{~g}$ or more pure alcohol.

$* * \mathrm{AF}=$ attributable fraction - that is, the proportion of disease under consideration that is attributable to alcohol.

$\dagger$ For liver cirrhosis, a combined estimate was derived for drinking categories II and III.

SOURCES: Unless otherwise specified, Gutjahr et al. 2001; for breast cancer and stroke, Ridolfo and Stevenson 2001; for hypertension, Corrao et al. 1999; for CHD,

drinking category III, Corrao et al. 2000.

associated with lower risk for CHD incidence and mortality, the lowest risk being found at 20 grams per day. For higher levels of average volume of alcohol consumption, the risk relationship reverses (Corrao et al. 2000;
Rehm et al. 1997), with average consumption of more than 70 grams per day associated with greater risk than the risks for abstainers. Several physiological mechanisms have been suggested to explain the protective effect of moderate drinking, including alcohol's role in reducing plaque deposits in arteries and the fact that moderate alcohol consumption protects against blood clot formation and promotes blood clot dissolution (Zakhari 1997; 


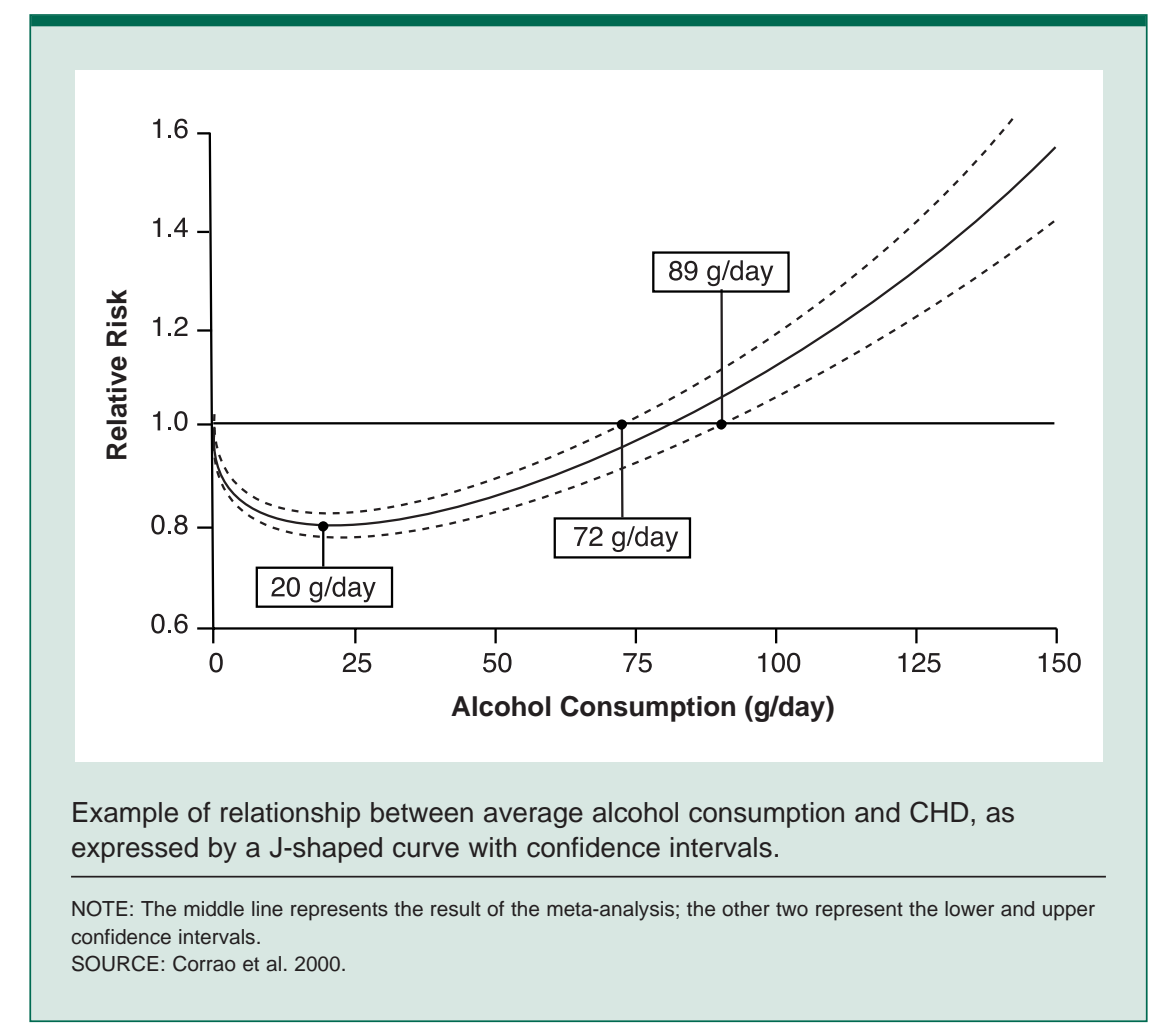

Rehm et al. 2003, in press b). However, most of these mechanisms are thought to apply only for cohorts in which a majority of respondents have reported a pattern of regular drinking without variability. As most of the studies analyzed by Corrao and colleagues (2000) used cohorts formed by groups with such patterns, further research is needed to determine how patterns of drinking other than regular light-to-moderate drinking are linked to CHD, especially among cohorts of usually light-to-moderate drinkers who sometimes binge drink.

Binge Drinking and CHD. A case control study in Australia (McElduff and Dobson 1997) compared 11,511 nonfatal and fatal cases of acute myocardial infarction, or coronary death, with 6,077 randomly selected people from the general population (i.e., control subjects). This study confirmed the already mentioned protective effect of moderate drinking, which was most pronounced for regular light-to-moderate drinkers. For example, men and women who drank one to two drinks per day on 5 or 6 days per week had one-third the risk of major coronary events compared with those who did not drink at all. The risk reduction was still marked when former drinkers were excluded. However, McElduff and Dobson (1997) found that binge drinkers (i.e., women who consumed five or more drinks on an occasion, or men who consumed nine or more drinks on an occasion) had higher risks for major coronary events than abstainers, even when overall volume of drinking was low. More recent studies that followed participants over time (i.e., prospective studies) also concluded that heavy drinking occasions increased the risk of CHD even in light-to-moderate drinkers (Murray et al. 2002; Trevisan et al. 2001a,b). This pattern effect persisted after controlling for average volume of drinking.
Binge Drinking and Other Negative Cardiovascular Effects. In addition to its effect on CHD, an irregular pat- tern of heavy drinking occasions appears to have a relationship with other types of cardiovascular death such as stroke or sudden cardiac death

(e.g., Wannemethee and Shaper 1992; Kauhanen et al. 1997). This relationship is consistent with the increased clotting and lowered threshold for ventricular fibrillation that occur after heavy drinking (see reviews by McKee and Britton 1998 and Rehm et al. 2003). (Heavy drinking appears to lower the threshold at which the ventricular heart muscle begins a rapid contraction pattern; without prompt intervention, this pattern prevents normal heart function and results in death.) Specifically, heavy drinking occasions have been shown to increase low density lipoproteins, which have been linked to negative cardiovascular outcomes. Although regular low-tomoderate drinking is associated with an increase in high density lipoproteins, which have been linked to favorable cardiovascular outcomes, this effect is not associated with irregular heavy drinking occasions (for a meta-analysis of the effect of moderate drinking on lipids and other physiological outcomes, see Rimm et al. 1999). In addition, irregular heavy drinking is associated with increased risk for the formation of blood clots within blood vessels (i.e., thrombosis), which occurs at the end of a heavy drinking occasion (Renaud and Ruf 1996). Finally, irregular heavy drinkers seem predisposed to structural (i.e., histological) changes in the heart muscle and the adjacent impulseconducting system, which regulate the threshold for ventricular fibrillation. In sum, a pattern of irregular heavy drinking occasions is mainly associated with physiological mechanisms that increase the risk of sudden cardiac death and other cardiovascular outcomes, whereas regular low-to-moderate alcohol consumption is associated with physiological mechanisms linked to favorable cardiac outcomes (for overviews of the effects of drinking pattern on CVD, see Puddey et al. 1999; Rehm et al. 2003). However, individual-level epidemiological studies on the consequences of drinking (i.e., studies, such as cohort and case control studies, which evaluate groups of individuals rather than entire populations) are still scarce, and at least 
one of them has found heavy drinking occasions to have no detrimental effects on morbidity (Murray et al. 1998).

Aggregate-Level Studies. Because there are few individual-level studies, much of the discussion on patterns of drinking and outcomes is based on aggregate-level studies, which evaluate whole populations rather than individual study participants. Much of this research emerged from the natural experiment provided by the Gorbachev anti-alcohol campaign in what was then the Soviet Union. In this campaign, all government departments were asked to develop strategies to reduce alcohol consumption, which was seen as hindering the country's development. Numerous measures were implemented to limit access to alcohol, including banning alcohol at the workplace, limiting alcohol sales hours, restricting the number of alcohol outlets, reducing alcohol production, and increasing prices by 25 percent in 1985 alone. In addition, the All-Union Voluntary Society for the Struggle for Sobriety was created in September 1985 to raise public awareness and mobilize the population (McKee 1999). During the period from 1984 to 1987, when estimated total alcohol consumption in the Soviet Union fell by about 25 percent (Shkolnikov and Nemtsov 1997), age-adjusted male deaths from circulatory disease fell by 9 percent (Leon et al. 1997). Because the Soviets did not use the ICD coding system, the term "circulatory disease" is used to refer to a category roughly equivalent to CVD (see Notzon et al. 1998 for a rigorous attempt to equate the two systems). After the end of the campaign, alcohol consumption increased by about 36 percent (from 1987 to 1993 ) and the circulatory disease death rate rose by 29 percent (between 1987 and 1994) (Leon et al. 1997).

Although researchers agree that changes in alcohol consumption and heavy drinking occasions played a role in the changes in circulatory mortality rates in the Soviet Union, the degree of alcohol's involvement is still questioned, as many other social changes occurred in the late 1980s and early 1990s. For example, the collapse of the Soviet Union contributed to a scarcity of medicine for treating hypertension and other forms of heart disease and to the collapse of the medical care infrastructure in general (e.g., Bobak and Marmot 1999; Notzon et al. 1998; McKee et al. 2001).

A few other aggregate-level studies have examined the influence of population-level alcohol consumption on CHD (i.e., ecological studies). Two studies that compared per capita alcohol consumption and CHD rates at a series of points in time (i.e., time-series analyses) (Hemström 2001; Skog 1983) failed to find effects even for countries where most drinking is believed to be regular and on average moderate, such as France and Italy (but see Gmel et al. 2003a). Other research has found that regions (e.g., Moscow, Scotland) or groups (e.g., German working males) with a tradition of heavy drinking or binge drinking occasions on weekends show disproportionally high CHD mortality on Mondays (Willich et al. 1994; Chenet et al. 1998; Evans et al. 2000).

\section{Effect of Drinking With Meals.}

Whether or not one drinks with meals has been found to be relevant to CHD. Trevisan and colleagues $(2001 a, b)$ found that people who drank alcohol mainly with meals and snacks had consistently lower risks for CHD than those who drank at other times, after adjustment for age, education, and volume of alcohol consumed. The mechanisms accounting for this difference in risk are still not clear, although a few have been proposed. Drinking with meals has been found to reduce blood pressure (Trevisan et al. 1987; Wu and Trevisan 2001; Foppa et al. 1999) and to positively affect lipids (Veenstra et al. 1990) and the dissolution of blood clots (Hendriks et al. 1994). In addition, the presence of food in the gastrointestinal tract may reduce alcohol absorption (Gentry 2000) or increase the rate at which alcohol is eliminated from the body (Ramchandani et al. 2001).
Beverage-Specific Effects. Researchers have long proposed that rates of $\mathrm{CHD}$ vary depending on the beverage consumed, ascribing a special beneficial effect to red wine. However, Rimm and colleagues (1996) reviewed the literature with respect to beveragespecific effects on CHD and did not find any systematic evidence that the protective effect was caused by or more prominent for any kind of beverage. Although many additional publications on this topic have appeared since their review, no consistent pattern of results has emerged. It is notable that researchers have found protective effects in Bavaria (Keil et al. 1997) and the Czech Republic (Bobak et al. 2000) similar to those effects found in Mediterranean countries. In Bavaria and the Czech Republic, beer is consumed the way wine is consumed in Mediterranean countries: regularly, on an almost daily basis, with meals. The study found that the manner of consumption was more important than the type of beverage.

The overall problem with studying beverage-specific effects is that beverage preference in most cultures is linked with other variables such as socioeconomic status and lifestyle variables (e.g., Bondy and Rehm 1998). These linkages may not be the same for different cultures, but many countries show clear covariation. For example, wine drinking in beer cultures is often associated with middle- and upperclass lifestyles. This makes it almost impossible to separate the effects of the beverages from other effects.

\section{Conclusions on Alcohol and CHD.}

What conclusions can be reached regarding the relationship between alcohol consumption and CHD? First, the physiological, individuallevel, and aggregate-level research converges to demonstrate the detrimental effect of irregular heavy drinking occasions. Both case control and cohort studies have supported this detrimental effect, and it has been corroborated by research using the natural experiment of the Gorbachev campaign. The result of irregular 
heavy drinking also has plausible physiological pathways.

Evidence that regular light-tomoderate drinking has a beneficial effect on the cardiovascular system comes from physiological and individuallevel epidemiological studies. However, aggregate-level, time-series analyses have failed to confirm this effect. Reasons for the different results for the two kinds of analyses are unknown. The time-series analyses may have been confounded by methodological problems, including a relatively short time period (Rehm and Gmel 2001; see also Hatanaka 1996; Greene 2000; Yaffee 2000). Ecological studies also have general limitations in elucidating causality. In contrast, the individual-level studies are based on stronger methodology. The accompanying sidebar reviews a number of methodological issues relevant to studies of alcohol-related morbidity and mortality.

\section{Alcohol Consumption and Cancer}

Many studies have reported consistent relationships between average consumption of alcohol and different types of cancer. (For examples of specific meta-analyses in the last five years in addition to the overviews of all alcohol-related conditions, see Bagnardi et al. 2001a,b; Dennis 2000; Ellison et al. 2001; Smith-Warner et al. 1998; Zeegers et al. 1999.) A recent series of meta-analyses showed that drinking on average 25 grams of pure alcohol per day was associated with significantly elevated cancer risks for the following sites: oral cavity and pharynx, esophagus, stomach, colon and rectum, liver, larynx, and female breast (Bagnardi et al. 2001a,b). However, for many cancer sites, even though there is a consistent relationship between average consumption of alcohol and risk for cancer, other criteria for determining causality are lacking. For example, for lung cancer, after adjusting for smoking, one meta-analysis showed a consistent effect with a relatively large effect size (English et al. 1995). However, because evidence for the possible biological mechanism was not conclusive and residual confounding from smoking could not be excluded, the authors excluded lung cancer from the list of diseases influenced by alcohol. A later meta-analysis showed only borderline significant effects (Bagnardi et al. 2001a,b), and the most recent review concluded that the evidence for a causal relationship was not sufficient (Bandera et al. 2001). Using consistent criteria, Rehm and colleagues (in press a) concluded that sufficient evidence of causality existed for the following cancer sites: oral cavity and pharynx, esophagus, liver, larynx, and female breast.

\section{Other Major Chronic Health Consequences of Alcohol Use}

Alcohol use is also related to chronic health consequences other than CVD and cancer. Most notable are neuropsychiatric and digestive diseases. The causal role of alcohol use in alcohol use disorders (e.g., alcohol dependence, alcohol abuse) is obvious. Alcohol use disorders are responsible for a considerable burden of disease in the United States and worldwide (e.g., Michaud et al. 2001). Moreover, alcohol use may cause depression (see Rehm et al. in press $b$ ). The fact that alcohol causes depression in some people does not exclude the possibility that some alcohol use disorders are caused by depression, or that, for some people with comorbid depression and alcohol use disorders, there may be a third cause. On the contrary, all three causal pathways seem to exist.

The association between alcohol use and liver cirrhosis is well established (e.g., Rodés et al. 1999). Researchers have considered whether irregular heavy drinking is a specific contributing factor to cirrhosis, in addition to the well-established relationship between cirrhosis and overall volume of drinking (Kozarevic et al. 1983; Rodés et al. 1999).

\section{ACute Consequences of Alcohol Use}

Alcohol use has been associated with increased risk of injury in a wide variety of situations including motor vehicle crashes, bicycling accidents, incidents involving pedestrians, falls, fires, injuries in sports and recreational activities, interpersonal violence, and self-inflicted injuries (Cherpitel 1992; Hingson and Howland 1987, 1993; U.S. Department of Health and Human Services [USDHHS] 1997, 2000; Martin 1982, Martin and Bachman 1997; Freedland et al. 1993; Hurst et al. 1994). Some evidence from emergency room studies and police records also suggests that the presence of alcohol in the body at the time of injury may be associated with greater severity of injury and less positive outcomes (Fuller 1995; Li et al. 1997). Overall, morbidity and mortality from traumatic injury is by far the most important health consequence of alcohol use in developed countries such as Canada or the United States (Single et al. 1999).

This section highlights research examining the relationships between acute health consequences and both average volume of alcohol consumption and drinking patterns. It focuses on unintentional injuries - specifically, traffic injuries - because most of the relevant research has been conducted in this area and because traffic crashes account for most alcohol-related unintentional injuries. For additional information on the relationship between alcohol and injuries, see the article by Gmel and Rehm in this issue.

Research has shown that risk of injury is positively related to average intake of alcohol, and that injury risk starts increasing at relatively low volumes of alcohol consumption (e.g., Cherpitel et al. 1995). Two studies of injury among adults ages 51 through 61 reported a U-shaped relationship between alcohol use and occupational injury (Zwerling et al. 1996) and traumatic deaths (Ross et al. 1990). That is, the rate of injury and death was higher among people who abstained from alcohol than among those who drank smallto-moderate amounts. The rate increased again with increasing alcohol use. This pattern may be explained by the fact that people who abstain

(Continued on page 48) 


\section{Methodological Issues Relevant to Studies of Alcohol-Related Morbidity and Mortality}

The relationships between alcohol consumption and disease outcomes have been reported in the alcohol literature based on the best available epidemiological evidence. However, this evidence is to some extent open to question because of the methodological limitations of the studies that produced it, particularly in relation to:

- Measurement of alcohol consumption and theorized exposure

- Measurement of outcome

- Selection of a comparison group

- Design-specific issues.

(See also Rehm and Gmel 2003.)

\section{Measurement of Alcohol Consumption and Theorized Exposure}

For individual-level epidemiological studies, alcohol consumption is usually determined using quantity and frequency $(\mathrm{QF})$ measures. These measures markedly underestimate the volume of drinking in developed countries (e.g., Midanik 1988, 1989; Rehm 1998). Thus, it is problematic to take them at face value- that is, to use them to derive risk relationships that state the risk related to the consumption of a certain volume of alcohol (e.g., grams of pure alcohol). Although no simple solution to this measurement problem exists, alcohol epidemiology has developed better ways to measure alcohol consumption, including measures of both volume of drinking at a certain point in time (e.g., during the last month) and volume accumulated over a longer period, such as the previous 5 years or the entire lifetime. Such measures may be necessary for estimating the associations with chronic diseases such as cancer.

One of these improved measures is the graduated frequency (GF) method, which asks respondents how often they consumed specific quantities, such as 10 to 12 drinks, in a given time period (Greenfield 2000). GF measures have been shown to underestimate volume of alcohol consumed to a smaller degree (Midanik 1994) than quantity and frequency measures and to correlate better with medical outcomes (Rehm et al. $1999 b$ ). The graduated frequency method also allows researchers to measure irregular heavy drinking patterns as well as volume of drinking at a certain point in time (Greenfield 2000; Rehm 2000). Thus, GF measures seem preferable to the QF measures currently used in medical epidemiology. However, it should be stressed that the method of measuring alcohol consumption used in an epidemiological study should be determined by the theoretically postulated relationship between drinking and disease, and based on the drinking patterns in the culture studied.

The relationship between alcohol consumption and outcome is often based on outcomes assessed at followup, often years after the baseline assessment, with analysis to adjust for the effects of several potential confounder variables such as smoking, age, or socioeconomic status. These procedures must assume that the baseline variables are stable over time, and that they are good indicators of the proposed relationship between alcohol consumption and disease (Sempos et al. 1993). For example, in assessing the relationship between average volume of alcohol consumption and incidence of breast cancer, it must be assumed that heavy consumption persists after baseline and is a good indicator of overall tissue exposure, which is the theoretical risk factor for breast cancer. If an association between two variables, such as heavy drinking and breast cancer, is real, any errors in measuring exposure will "dilute" the strength of the relationship. Therefore, the size of the real effects is often underestimated because of the inaccurate measurement of alcohol consumption at baseline (Clarke et al. 1999). One way to avoid this dilemma is to use measures such as lifetime drinking history in addition to point measures (Russell et al. 1997). The lifetime drinking history is clearly capable of yielding a closer approximation of a theorized lifetime cumulative exposure, which is essential when studying chronic diseases for which accumulated volume of alcohol consumption is the important factor in risk.

For acute outcomes, the usual quantity and frequency measures also do not correspond to the theoretical exposure, which may be BAC or intoxication before the event (e.g., Rossow et al. 2001). Here, 
objectively measuring $\mathrm{BAC}$ or asking directly for degree of intoxication would be preferred options.

Although this sidebar does not review all possible means of measuring alcohol consumption, the examples given should suffice to make the point that the measure of alcohol consumption used in epidemiological studies should reflect the theory underlying the research.

\section{Measurement of Outcome}

Mortality can usually be measured with relatively little error. Morbidity is more problematic.

On the one hand, many medical epidemiological studies take pains to objectively assess and validate the outcome under consideration. Examples include two coronary heart disease (CHD) studies, the National Health and Nutrition Examination Survey I (NHANES I) followup study on CHD incidence (Sempos et al. 1994), and the World Health Organization MONItoring Trends and Determinants in CArdiovascular Diseases (MONICA) study, a long-term, multinational study on CHD (Tunstall-Pedoe et al. 1999).

On the other hand, studies based on alcohol surveys often measure morbidity by self-assessment, sometimes even including an attribution of causality in the questions respondents are asked (e.g." "Was there ever a time when you felt your alcohol use had a harmful effect on your physical health?"). It is impossible to establish causal relationships with these types of questions (Rehm et al. 1999a; Gmel et al. 2000). It is not even possible to establish correlation based on the results of such surveys, beyond the fact that people subjectively believe that there is a relationship between alcohol use and health outcomes. The history of medicine has often shown that such subjective assessment of causality and correlation may not be valid. For instance, women with breast cancer have subjectively attributed their cancer to their number of sexual partners, a causal relation that has no objective basis (Geyer 2000). Similarly, people may attribute health and other problems to alcohol in cases where there is no real relationship. As a consequence, future studies linking alcohol and disease should try to combine the rigorous objective assessment of outcomes used in medical epidemiology with state-ofthe-art measurement of alcohol epidemiology.

\section{Selection of a Comparison Group}

Studies of alcohol-related health outcomes often use abstainers as a comparison group. Abstainers, however, are not a homogeneous group, at least in devel- oped countries. Many people stop drinking because they have become sick, thus increasing the relationship between abstention and disease (Shaper 1990). Studies of disease risk that compare different levels of drinking and no drinking may overestimate the protective effect of light-to-moderate drinking if abstainers are not separated into lifetime abstainers and former drinkers (Rehm et al. 2001). For example, when the relationship between alcohol use and disease forms a J-shaped curve (see the figure in the article), the increased risk observed for abstainers may reflect the fact that some former drinkers became current abstainers because of health problems. Even if this distinction is made, interpreting risk differences for current drinkers compared with lifetime abstainers may be difficult, because lifetime abstainers in many societies differ from the general population in several other ways, such as diet, religion, or socioeconomic status (e.g., Bondy and Rehm 1998). Because long-term studies cannot manipulate abstention status experimentally, there is no final way to determine the causal influence of alcohol consumption. However, statistical control of potential confounders is possible.

\section{Design-Specific Issues}

Of the two major categories of research designs, individual-level studies produce results that deserve greater attention than the results of aggregate-level, or ecological, studies, especially when the individual-level results are corroborated by evidence from physiological experiments. However, specific aggregate-level examples with interventions, such as the study of the Gorbachev anti-alcohol campaign (described in the article), play an important role in alcohol epidemiology.

The Gorbachev campaign is an exception for several reasons: It was a natural experiment with a purposeful change in one variable; it affected a large outcome category (mortality from all causes); its effects cannot be explained by changes in the system used to document causes of death or other changes; and it had very large effects. Other ecological analyses in the alcohol field tend to show correlations over time or countries, which can hardly be interpreted because confounding cannot be excluded.

Generally, however, more value is placed on individual-level analysis than on ecological analysis. The two individual-level designs most often used are case control and cohort designs. Cohort studies may be especially problematic in alcohol epidemiology. First, many large-scale cohorts are selected in a way to 
minimize dropouts (i.e., based on their members' availability for repeated followups). As a result, nurses, doctors, and other health professionals often make up these cohorts. Selecting cohorts on this basis reduces the variation within cohorts with respect to alcohol consumption. As a consequence, the effects of certain drinking patterns cannot be explored in such cohorts. Some cohort studies - such as the American Cancer Society's Cancer Prevention Study II, a nonrepresentative general population study based on the American Cancer Society's members and friends (Thun et al. 1997) make use of a wider range of drinking styles. These cohort studies, however, do not include some patterns of drinking that are customary in other parts of the world or in other U.S. population subgroups (e.g., Native Americans, the homeless, and other disadvantaged groups), and thus the effects of these drinking patterns cannot be studied. These limitations of cohort studies for use in alcohol epidemiology are purely practical and do not change the theoretical advantages of cohorts over case control studies. However, if the relevant behavior is not present in a cohort, no conclusions can be drawn. In sum, in many cohorts studied in medical epidemiology, certain patterns are either not represented or represented in a manner that does not allow for analysis. Thus, future cohort studies should include people with more varied consumption patterns, such as irregular heavy drinking.

\section{—Jürgen Rehm, Gerhard Gmel, Christopher T. Sempos, and Maurizio Trevisan}

\section{References}

BONDY, S., AND REHM, J. The interplay of drinking patterns and other determinants of health. Drug and Alcohol Review 17:399-412, 1998.

Clarke, R.; Shipley, M.; Lewington, S.; ET AL. Underestimation of risk associations due to regression dilution in long-term follow-up of prospective studies. American Journal of Epidemiology 150:341-353, 1999.

GEYER, S. The role of social and psychosocial factors in the development and course of cancer. Wiener Klinische Wochenschrift 112:986-994, 2000.

GMEL, G.; ReHM, J.; RoOM, R.; AND GREENFIELD, T.K. Dimensions of alcohol-related social harm in survey research. Journal of Substance Abuse 12:113-138, 2000.

GREENFIELD, T.K. Ways of measuring drinking patterns and the difference they make: Experience with graduated frequencies. Journal of Substance Abuse 12:33-50, 2000.

MIDANIK, L.T. Validity of self-reported alcohol use: A literature review and assessment. British Journal of Addiction 83:1019-1029, 1988.
MiDANIK, L.T. Perspectives on the validity of self-reported alcohol use. British Journal of Addiction 84:1419-1423, 1989.

MIDANIK, L.T. Comparing usual quantity/frequency and graduated frequency scales to assess yearly alcohol consumption: Results from the 1990 U.S. National Alcohol Survey. Addiction 89:407-412, 1994.

REHM, J. Measuring quantity, frequency and volume of drinking. Alcoholism: Clinical and Experimental Research 22:4S-14S, 1998.

ReHM, J. Re: Alcohol intake assessment: The sober facts. American Journal of Epidemiology 151:436-438, 2000.

REHM, J., and GMEL, G. Alcohol consumption and total mortality/ morbidity: Definitions and methodological implications. Best Practices \& Research Clinical Gastroenterology 17:497-505, 2003.

REHM, J.; FRICK, U.; AND BONDY, S. A reliability and validity analysis of an alcohol-related harm scale for surveys. Journal of Studies on Alcohol 60:203-208, 1999a.

Rehm, J.; Greenfield, T.K.; Walsh, G.; ET Al. Assessment methods for alcohol consumption, prevalence of high risk drinking and harm: A sensitivity analysis. International Journal of Epidemiology 28:219-224, 1999b.

ReHM, J.; GUTJAHR, E.; AND GMEL, G. Alcohol and all-cause mortality: A pooled analysis. Contemporary Drug Problems 28:337-361, 2001.

Rossow, I.; Pernanen, K.; And Rehm, J. Accidents, suicides and violence. In: Klingemann, H., and Gmel, G., eds. Mapping the Social Consequences of Alcohol Consumption. Dordrecht, Netherlands: Kluwer Academic Publishers, 2001. pp. 93-112.

Russell, M.; Marshall, J.R.; Trevisan, M.; ET Al. Test-retest reliability of the Cognitive Lifetime Drinking History. American Journal of Epidemiology 146:975-981, 1997.

SEMPOS, C.T.; Flegal, K.M.; JoHnSON, C.L.; ET AL. Issues in the long-term evaluation of diet in longitudinal studies. Journal of Nutrition 123:405-412, 1993.

Sempos, C.T.; LoOKer, A.C.; Gillum, R.F.; AND Makuc, D.M. Body iron stores and the risk of coronary heart disease. New England Journal of Medicine 330:1119-1124, 1994.

SHAPER, A.G. Alcohol and mortality: A review of prospective studies. British Journal of Addiction 85:837-847, 1990.

Thun, M.J.; Peto, R.; Lopez, A.D.; ET AL. Alcohol consumption and mortality among middle-aged and elderly U.S. adults. New England Journal of Medicine 337:1705-1714, 1997.

Tunstall-Pedoe, H.; KuUlasmaa, K.; MähÖnen, M.; et AL. Contribution of trends in survival and coronary-event rates to changes in coronary heart disease mortality: 10-year results from $37 \mathrm{WHO}$ MONICA Project populations. Lancet 353:1547-1557, 1999. 


\section{(Continued from page 44)}

from alcohol may have existing health problems or cognitive deficits that are, in turn, related to injury risk (Zwerling et al. 1996).

Several patterns of drinking have been related to injury risk. Frequent heavy drinking and frequent drunkenness are both associated with injury, particularly injury resulting from violence (Cherpitel 1996). Frequency of heavy drinking has also been associated with a greater likelihood of death from injury than from other causes ( $\mathrm{Li}$ et al. 1994).

Research has also found that people who consume relatively large amounts of alcohol on some occasions and whose highest amounts are markedly greater than their average amount per occasion have the greatest risk for injury related to drinking and driving (Gruenewald and Nephew 1994; Gruenewald et al. 1996a,b; Treno and Holder 1997; Treno et al. 1997).

A series of retrospective case control studies have compared the blood alcohol concentration (BAC) levels of people who had experienced trauma (i.e., traffic crashes or other incidents) with the BAC levels of people, usually from the general population, who were not involved in trauma (Cherpitel 1992; Freedland et al. 1993; Fuller 1995; Stoduto et al. 1993; USDHHS 1997; Hurst et al. 1994). In the largest such study, Borkenstein and colleagues (1964) compared the BAC levels of 5,985 drivers involved in traffic crashes with those of 7,590 control drivers in Grand Rapids, Michigan, in 1962 and 1963. For the control sample, police stopped vehicles at preselected sites and times, after which members of the research team requested a voluntary breath sample exclusively for research purposes. A proper statistical analysis of this study (Hurst et al. 1994) found that all levels of BAC were associated with a higher risk of crashes, relative to a BAC of zero, and that the risk of injury increased exponentially with markedly higher BACs.

There are clear reasons why alcohol is related to all kinds of trauma and injury. Even moderate doses of alcohol have cognitive and psychomotor effects that are relevant to the risk of injury, such as effects on reaction time, cognitive processing, coordination, and vigilance (Moskowitz and Robinson 1988; USDHHS 1997; Krüger et al. 1993; Eckardt et al. 1998). Eckardt and colleagues (1998) concluded that the threshold for negative effects on psychomotor tasks is generally found around 0.04 to 0.05 percent BAC.

Driving experience diminishes the adverse impact of alcohol on performance (Preusser et al. 1978). Research has also shown that the relative risk of a fatal crash increases with increasing BAC for each age group but that fatal crash risk for drivers ages 16 to 19 years is higher than the risk for other age groups at all BACs, including zero. This is a result of younger drivers' lower tolerance for alcohol and their relative inexperience in driving (Mayhew et al. 1985, 1986; Zador 1991).

Dose-response relationships observed in experimental data are not always linear. For example, a recent study with human participants (Lloyd and Rogers 1997) assessed the effects of low doses of alcohol given with a meal and found that a dose of 8 grams of pure alcohol resulted in improved performance on a complex cognitive task in comparison with no alcohol intake, but that 24 grams of alcohol produced impaired performance (Eckardt et al. 1998).

In summary, the evidence indicates that the amount of alcohol consumed per occasion - specifically, the BAC is the critical feature in determining risk of injury. BACs as low as 0.04 to 0.05 percent may cause psychomotor impairments that lead to increased risk of injury while driving or operating machinery. Alcohol use can be established as a contributing factor in traffic crashes for the following reasons:

- Alcohol is clearly associated with the outcome (i.e., consumption of alcohol increases the risk of being involved in traffic crashes).
- There is a dose-response relationship: the higher the BAC, the higher the chance for injury.

- There is physiological evidence for the relationship.

- Interventions that reduce drinking and driving also reduce alcoholrelated traffic crashes. For example, Shults and colleagues (2001) reported in a meta-analysis that random breath testing programs or selective breath testing checkpoints were effective in reducing the mortality of traffic crashes by 18 percent and the number of fatal crashes by 20 percent, in comparison with locations that did not have such programs or checkpoints.

Establishing causality for other forms of alcohol-related injuries is more difficult, even though a strong link may exist. Further research is needed in this area.

\section{Alcohol and Summary Measures of Health}

This article has reviewed research on the observed relationships between alcohol consumption and disease. Many relationships exist, both detrimental and beneficial. This section will review what is known about alcohol and summary measures of health, which are measures that give a general picture of the health of a population, rather than any specific disease risk. One classic summary measure is mortality from all causes. The relationship between average volume of consumption and all-cause mortality in males and females older than 45 is J-shaped, as evidenced by recent meta-analyses (English et al. 1995; Rehm et al. 2001b; Gmel et al. 2003b). In younger cohorts, a linear relationship prevailsthat is, light-to-moderate drinking has no protective effect (Rehm et al. 2001b). Indications are that pattern of drinking influences all-cause mortality in all ages as well (Rehm et al. 2001a).

All-cause mortality may not, however, be the best summary indicator 
for measuring alcohol's impact on health. As indicated above, alcohol use has stronger links to morbidity and disability than to mortality (Murray and Lopez 1997). Thus, a suitable summary indicator (Murray et al. 2000) should integrate data on mortality, morbidity, and disability. Such a summary indicator should also be based on a time measure, such as years of life lost. The Disability Adjusted Life Year (DALY) concept fulfills these requirements ideally. It is a measure that combines years of life lost because of early mortality (i.e., death before the life expectancy in the country with the highest life expectancy worldwide [currently Japan]) with years of life lost to imperfect health (Murray et al. 2000). The relationship between alcohol consumption and DALYs demonstrates that a substantial burden of disease is attributable to alcohol consumption. In 1990 this was estimated as globally higher than the burden of disease attributable to tobacco, even after subtracting the beneficial effects on CHD (Murray and Lopez 1996, 1997).

\section{Conclusion}

Alcohol use is related to a huge health burden in the United States and most countries worldwide, even after discounting for its beneficial effects. In considering this burden, especially for chronic disease, one must keep in mind the limitations of epidemiological studies, which are mostly observational in nature (e.g., cohort studies and case control studies, as described above; also see the sidebar). However, most of the relationships between alcohol use and disease outcomes have also been corroborated by experimental physiological research.

Much of the alcohol-related health burden could be avoided by initiating or strengthening policy measures proven to be effective in reducing alcohol use and related problems, such as taxing consumption, restricting access to alcohol, and random breath testing (Edwards et al. 1994).
Some of these measures (e.g., taxation, restricting access) have been shown to reduce the social harm caused by alcohol consumption as well. Given the size of the burden of disease related to alcohol use and the availability of effective countermeasures, there seems to be no justification for continuing the status quo.

\section{ACKNOWLEDGMENT}

We would like to thank Mary Jane Ashley, Susan Bondy, and Eric Single, all of whom extensively contributed to earlier reviews of the literature.

\section{REFERENCES}

BagnaRdi, V.; BlangiaRdo, M.; LA Vecchia, C.; ET AL. Alcohol consumption and the risk of cancer: A meta-analysis. Alcohol Research \& Health 25(4):263-270, 2001a.

BagnaRdi, V.; Blangiardo, M.; La Vecchia, C.; ET AL. A meta-analysis of alcohol drinking and cancer risk. British Journal of Cancer 85(11): 1700-1705, 2001b.

Bandera, E.V.; Freudenheim, J.L.; AND Vena, J.E. Alcohol and lung cancer: A review of the epidemiologic evidence. Cancer Epidemiology, Biomarkers \& Prevention 10:813-821, 2001.

BOBAK, M., AND MARMOT, M. Alcohol and mortality in Russia: Is it different than elsewhere? Annals of Epidemiology 9:335-338, 1999.

BobaK, M.; SKODOVA, Z.; AND MaRmot, M. Effect of beer drinking on risk of myocardial infarction: Population based case-control study. British Medical Journal 320:1378-1397, 2000.

BONDY, S., AND REHM, J. The interplay of drinking patterns and other determinants of health. Drug and Alcohol Review 17:399-412, 1998.

BORKENSTEIN, R.F.; CROWTHER, R.F.; AND Shumate, R.P. The Role of the Drinking Driver in Traffic Accidents. Bloomington, IN:

Department of Police Administration, 1964.

Chenet, L.; McKee, M.; LeOn, D.; ET AL. Alcohol and cardiovascular mortality in Moscow: New evidence of a causal association. Journal of Epidemiology and Community Health 52:772-774, 1998.

Cherpitel, C.J. The epidemiology of alcoholrelated trauma. Alcohol Health \& Research World 16:191-196, 1992.

CHERPITEL, C.J. Drinking patterns and problems and drinking in the event: An analysis of injury by cause among casualty patients. Alcoholism: Clinical and Experimental Research 20:1130-1137, 1996.
Cherpitel, C.J.; TAM, T.; MidAniK, L.; ET AL. Alcohol and non-fatal injury in the U.S. general population: A risk function analysis. Accident Analysis Prevention 27:651-661, 1995.

Corrao, G.; Bagnardi, V.; Zambon, A.; ET AL. Exploring the dose-response relationship between alcohol consumption and the risk of several alcohol-related conditions: A meta-analysis. Addiction 94:1551-1573, 1999.

Corrao, G.; Rubbiati, L.; Bagnardi, V.; et al. Alcohol and coronary heart disease: A meta-analysis. Addiction 95:1505-1523, 2000.

DeNNIS, L.K. Meta-analysis for combining relative risks of alcohol consumption and prostate cancer. Prostate 42(1):56-66, 2000.

EckardT, M.J.; File, S.E.; Gessa, G.L.; ET AL. Effects of moderate alcohol consumption on the central nervous system. Alcoholism: Clinical and Experimental Research 22:998-1040, 1998.

EDWARDS, G.; ANDERSON, P.; BABOR, T.F.; ET AL. Alcohol Policy and the Public Good. Oxford: Oxford University Press, 1994.

Ellison, R.C.; Zhang, Y.; McLennan, C.E.; ET AL. Exploring the relation of alcohol consumption to risk of breast cancer. American Journal of Epidemiology 154(8):740-747, 2001.

English, D.R.; Holman, C.D.J.; Milne, E.; ET AL. The Quantification of Drug Caused Morbidity and Mortality in Australia 1995. Canberra: Commonwealth Department of Human Services and Health, 1995.

Evans, C.; Chalmers, J.; Capewell, S.; et al. "I don't like Mondays"-Day of the week of coronary heart disease deaths in Scotland: Study of routinely collected data. British Medical Journal 320:218-219, 2000.

Foppa, M.; Fuchs, F.D.; Preissler, L.; ET AL. Wine with the noon meal lowers post meal blood pressure: Randomized trial in centrally obese hypertensive patients. Hypertension 33:119, 1999.

Freedland, E.; McMicken, D.; AND D’Onofrios, G. Alcohol and trauma. Emergency Medicine Clinics of North America 11:225-239, 1993.

FULLER, M. Alcohol use and injury severity in trauma patients. Journal of Addictive Diseases 14:47-53, 1995.

GENTRY, R.T. Effect of food on the pharmocokinetics of alcohol consumption. Alcoholism: Clinical and Experimental Research 24:403404, 2000.

Gmel, G.; ReHM, J.; AND Frick, U. Trinkmuster, Pro-Kopf-Konsum von Alkohol und Koronare Mortalität. Sucht 49(2):95-104, 2003a.

GMel, G.; GutJahr, E.; AND ReHm, J. How stable is the risk curve between alcohol and allcause mortality and what factors influence the shape? A precision-weighted hierarchical meta-analysis. European Journal of Epidemiology 18(7): 631-642, $2003 b$. 
GoerdT, A.; Koplan, J.P.; Robine, J.M.; ET AL. Non-fatal health outcomes: Concepts, instruments and indicators. In: Murray, C.J.L., and Lopez, A.D., eds. The Global Burden of Disease: A Comprehensive Assessment of Mortality and Disability from Diseases, Injuries and Risk Factors in 1990 and Projected to 2020. Boston: Harvard School of Public Health on behalf of the World Health Organization and the World Bank, 1996. pp. 201-246.

Gordis, L. Epidemiology. 2d ed. New York: W.B. Saunders, 1999.

GreENE, W.H. Econometric Analysis. Upper Saddle River, NJ: Prentice Hall, 2000.

GRUENEWALd, P.J.; AND NePheW, T. Drinking in California: Theoretical and empirical analyses of alcohol consumption patterns. Addiction 89:707-723, 1994.

Gruenewald, P.J.; Mitchell, P.R.; AND TRENO, A.J. Drinking and driving: Drinking patterns and drinking problems. Addiction 91:1649, 1996a.

GRUenewald, P.J.; TRENO, A.J.; AND

MitCheLL, P.R. Drinking patterns and drinking behaviours: Theoretical models of risky acts. Contemporary Drug Problems 23:407-440, 19966 .

Gutjahr, E.; Gmel, G.; AND ReHM, J. Relation between average alcohol consumption and disease: An overview. European Addiction Research 7:117-127, 2001.

HatanaKa, M. Time-Series-Based Econometrics: Unit Roots and Co-Integration. New York: Oxford University Press, 1996.

Hemström, Ö. Per capita alcohol consumption and ischaemic heart disease mortality. Addiction 96: S93-S112, 2001.

Hendriks, H.F.; Veenstra, J.; Velthuis-Te WIERIK, E.J.; ET AL. Effects of moderate dose of alcohol with evening meal on fibrinolytic factors. British Medical Journal 308:1003-1006, 1994.

Hingson, R., AND Howland, J. Alcohol as a risk factor for injury or death resulting from accidental falls: A review of the literature. Journal of Studies on Alcohol 48:212-219, 1987.

Hingson, R., AND Howland, J. Alcohol and non-traffic unintended injuries. Addiction 88: 877-883, 1993.

Hurst, P.M.; Harte, W.J.; AND FirTh, W.J. The Grand Rapids dip revisited. Accident Analysis and Prevention 26:647-654, 1994.

Kauhanen, J.; Kaplan, G.A.; Goldberg, D.D.; ET AL. Frequent hangovers and cardiovascular mortality in middle-aged men. Epidemiology 8:310-314, 1997.

Keil, U.; Chambless, L.E.; DÖring, A.; ET AL. The relation of alcohol intake to coronary heart disease and all-cause mortality in a beer-drinking population. Epidemiology 8:150-156, 1997.

Klingemann, H., AND GMel, G. Mapping the Social Consequences of Alcohol Consumption. Dordrecht, Netherlands: Kluwer Academic Publishers, 2001.
Kohlmeier, L., And Mendez, M. Controversies surrounding diet and breast cancer. Proceedings of the Nutrition Society 56:369-382, 1997.

KozAReVIC, D.; VoJvOdic, N.; Gordon, T.; ET AL. Drinking habits and death: The Yugoslavia cardiovascular disease study. International Journal of Epidemiology 12(2):145-150, 1983.

KrÜGer, H.P.; Utzelmann, H.D.; Berghaus, G.; AND KROJ, G. Effects of low alcohol dosages: A review of the literature. In: Alcohol, Drugs and Traffic Safety-T92. Cologne, Germany: Verlag TUV Rheinland, 1993. pp. 763-778.

LEON, D.A.; ChENET, L.; SHKOlNiKov, V.M.; ET AL. Huge variation in Russian mortality rates 1984-94: Artefact, alcohol, or what? Lancet 350: 383-388, 1997.

LI, G.; SMITH, G.D.; AND BAKER, S.P. Drinking behavior in relation to cause of death among U.S adults. American Journal of Public Health 84: 1402-1406, 1994.

LI, G.; KeYl, P.M.; SMITH, G.S.; AND BAKER, S.P. Alcohol and injury severity: Reappraisal of the continuing controversy. Journal of Trauma 42:562-569, 1997.

Lloyd, H.M., AND Rogers, P.J. Mood and cognitive performance improved by a small amount of alcohol given with a lunchtime meal. Behavioural Pharmacology 8:88-195, 1997.

MarTin, S.E. The epidemiology of alcoholrelated interpersonal violence. Alcohol Health \& Research World 16:230-237, 1982.

Martin, S.E., AND BACHMAN, R. The relationship of alcohol to injury in assault cases. In: Galanter, M., ed. Recent Developments in Alcoholism. New York: Plenum Press, 1997. pp. 41-56.

MAYHEW, D.R.; SimPSON, M.H.; KAYE, S.; AND MeIER, G. Alcohol, age, and risk of road accident involvement. In: Kaye, S., and Meier, G.W., eds., Alcohol, Drugs and Traffic Safety. Proceedings of the Ninth International Conference on Alcohol, Drugs and Traffic Safety. San Juan, Puerto Rico, November 1983. Washington, DC: U.S. Government Printing Office, 1985. pp. 937-947.

MayHew, D.R.; Donelson, A.C.; BeIRness, D.J.; AND Simpson, M.H. Youth, alcohol and the relative risk of crash involvement. Accident Analysis Prevention 18:273-288, 1986.

McElduff, P., ANd Dobson, A.J. How much alcohol and how often? Population based casecontrol study on alcohol consumption and risk of a major coronary event. British Medical Journal 314:1159-1164, 1997.

McKeE, M. Alcohol in Russia. Alcohol \& Alcoholism 34(6):824-829, 1999.

McKeE, M., AND BRITTON, A. The positive relationship between alcohol and heart disease in Eastern Europe: Potential physiological mechanisms. Journal of the Royal Society of Medicine 91:402-407, 1998.

McKee, M.; ShKOLNIKOV, V.; AND LeON, D.A. Alcohol is implicated in the fluctuations in car- diovascular disease in Russia since the 1980s. Annals of Epidemiology 11:1-6, 2001.

Michaud, C.M.; Murray, C.J.; And Bloom, B.R. Burden of disease-implications for future research. JAMA: Journal of the American Medical Association 285(5):535-539, 2001.

Moskowitz, H., AND Robinson, C. Effects of Low Doses of Alcohol on Driving-Related Skills: A Review of the Evidence. Washington, DC:

National Highway Traffic Safety Administration, 1988.

MurRaY, C.J.L., AND LOPEZ, A.D. Quantifying the burden of disease and injury attributable to ten major risk factors. In: Murray, C.J.L., and Lopez, A.D., eds. The Global Burden of Disease: A Comprehensive Assessment of Mortality and Disability from Diseases, Injuries and Risk Factors in 1990 and Projected to 2020. Boston: Harvard School of Public Health on behalf of the World Health Organization and the World Bank, 1996. pp. 295-324.

Murray, C.J.L., AND LOPEZ, A.D. Global mortality, disability, and the contribution of risk factors: Global burden of disease study. Lancet 349:1436-1442, 1997.

MurRay, C.J.L.; SAlomon, J.A.; AND Mathers, C. A critical examination of summary measures of population health. Bulletin of the World Health Organization 78:981-994, 2000.

Murray, R.P.; IstVAn, J.A.; DANIELs, K.; AND BEAUDOIN, C.M. Alcohol and morbidity in the Lung Health Study. Journal of Studies on Alcohol 59:250-257, 1998 .

Murray, R.P.; CONNETT, J.E.; Tyas, S.L.; ET AL. Alcohol volume, drinking pattern, and cardiovascular disease morbidity and mortality: Is there a U-shaped function? American Journal of Epidemiology 155:242-248, 2002.

Notzon, F.C.; Komarov, Y.M.; Ermakov, S.P.; ET AL. Causes of declining life expectancy in Russia. JAMA: Journal of the American Medical Association 279:793-800, 1998.

Preusser, D.F.; Ulmer, R.G.; AND ADAms, J.R. Driver record evaluation of a drinking driver rehabilitation program. Journal of Safety Research 8:98-105, 1978.

Puddey, I.B; Rakic, V.; Dimmitt, S.B.; AND BEILIN, L.J. Influence of pattern of drinking on cardiovascular disease and cardiovascular risk factors-A review. Addiction 94:649-663, 1999.

RamCHANDANI, V.A.; KWo, P.Y.; AND LI, T.K. Effect of food and food composition on alcohol elimination rates in healthy men and women. Journal of Clinical Pharmacology 41:1345-1350, 2001.

ReHM, J. Concepts, dimensions and measures of alcohol-related social consequences. A basic framework for alcohol-related benefits and harm. In: Klingemann, H., and Gmel, G., eds. Mapping the Social Consequences of Alcohol Consumption. Dordrecht, Netherlands: Kluwer Academic Publishers, 2001. pp. 11-19. 
ReHm, J., AND GMeL, G. Gaps and needs in international alcohol epidemiology. Journal of Substance Use 5:6-13, 2000.

ReHm, J., AND Gmel, G. Aggregate time-series regression in the field of alcohol. Addiction 96:945-954, 2001.

ReHM, J.; Bondy, S.; SEMPos, C.T.; AND VUONG, C.V. Alcohol consumption and coronary heart disease morbidity and mortality. American Journal of Epidemiology 146:495-501, 1997.

Rehm, J.; Greenfield, T.K.; And Rogers, J.D. Average volume of alcohol consumption, patterns of drinking and all-cause mortality. Results from the U.S. National Alcohol Survey. American Journal of Epidemiology 153:64-71, 2001a.

Rehm, J.; GuTJAhr, E.; AND GMEL, G. Alcohol and all-cause mortality: A pooled analysis. Contemporary Drug Problems 28:337-361, 2001 b.

Rehm, J.; Sempos, C.T.; AND TRevisan, M. Average volume of alcohol consumption, patterns of drinking and risk of coronary heart disease- $\mathrm{A}$ review. Journal of Cardiovascular Risk 10(1):1520, 2003.

Rehm, J.; RoOm, R.; Graham, K.; ET AL. The relationship of average volume of alcohol consumption and patterns of drinking to burden of disease-An overview. Addiction, in press $a$.

Rehm, J.; RoOm, R.; Monteiro, M.; ET AL. Alcohol as a risk factor for burden of disease. In: Ezzati, M.; Lopez, A.D.; Rodgers, A.; and Murray, C.J.L., eds. Comparative Quantification of Health Risks: Global and Regional Burden of Disease Due to Selected Major Risk Factors.

Geneva: World Health Organization, in press $b$.

RENAUd, S.C., AND RUF, J.C. Effects of alcohol on platelet function. Clinica Chimica Acta 246: 77-89, 1996.

Ridolfo, B., and Stevenson, C. The Quantification of Drug-Caused Mortality and Morbidity in Australia 1998. Canberra: Australian Institute of Health and Welfare, 2001.

Rimm, E.B.; Klatsky, A.; Grobbee, D.; AND STAMPFER, M. Review of moderate alcohol consumption and reduced risk of coronary heart disease: Is the effect due to beer, wine or spirits? British Medical Journal 312:731-735, 1996.

Rimm, E.B.; Williams, P.; Fosher, K.; ET AL. Moderate alcohol intake and lower risk of coronary heart disease: Meta-analysis of effects on lipids and haemostatic factors. British Medical Journal 319:1523-1528, 1999.

Rodés, J.; SAlaspuro, M.; AND SOREnSEn, T.I.A. Alcohol and liver disease. In: MacDonald, I., ed.. Health Issues Related to Alcohol Consumption, $2 \mathrm{~d}$ ed. Oxford: Blackwell Science, 1999. pp. 395-450.
Ross, R.; BernsteIn, L.; Trent, L.; ET AL. A prospective study of risk factors for traumatic deaths in a retirement community. Alcoholism: Clinical and Experimental Research 20:1130-1137, 1990.

Shrolnikov, V.M.; AND NemTsov, A. The antialcohol campaign and variations in Russian mortality. In: Bobadilla, J.L.; Costello, C.A.; and Mitchell, F., eds. Premature Death in the New Independent States. Washington, DC: National Academy Press, 1997. pp. 239-261.

Shults, R.A.; Elder, R.W.; SLEET, D.A.; ET AL. Reviews of evidence regarding interventions to reduce alcohol-impaired driving. American Journal of Preventive Medicine 21(4S):66-88, 2001.

Single, E.; Robson, L.; Rehm, J.; And Xie, X. Morbidity and mortality attributable to alcohol, tobacco, and illicit drug use in Canada. American Journal of Public Health 89:385-390, 1999.

SKOG, O.J. Methodological problems in the analysis of temporal covariation between alcohol consumption and ischaemic heart disease. British Journal of Addiction 78:157-172, 1983.

SMITH-WARNER, S.A.; SPIEGELMAN, D.; YAUN, S.S.; ET AL. Alcohol and breast cancer in women: A pooled analysis of cohort studies. JAMA: Journal of the American Medical Association 279(7): 535-540, 1998.

Stoduto, G.; Vingilis, E.; KapUR, B.; ET AL. Alcohol and drug use among motor vehicle collision victims admitted to a regional trauma unit: Demographic, injury and crash characteristics. Accident Analysis and Prevention 25:411-420, 1993.

Treno, A.J., And Holder, H.D. Measurement of alcohol-involved injury in community prevention: The search for a surrogate III. Alcoholism: Clinical and Experimental Research 21:1695-1703, 1997.

Treno, A.J.; Gruenewald, P.J.; AND PONICKI, W.R. The contribution of drinking patterns to the relative risk of injury in six communities: A self-report based probability approach. Journal of Studies on Alcohol 58:372-381, 1997.

Trevisan, M.T.; Krogh, V.; Farinaro, E.; ET AL. Alcohol consumption, drinking pattern and blood pressure: Analysis of data from the Italian National Research Council Study. International Journal of Epidemiology 16:520-527, 1987.

Trevisan, M.T.; Ram, M.; Hovey, K.; ET AL. Alcohol drinking patterns and myocardial infarction. American Journal of Epidemiology 153(11): S97, 2001a.

Trevisan, M.T.; Schisterman, E.; Mennotti, A.; ET AL. Drinking pattern and mortality: The Italian Risk Factor and Life Expectancy Pooling Project. Annals of Epidemiology 11:312-319, 20016.

U.S. Department of Health and Human Services (USDHHS). Ninth Special Report to the U.S.
Congress on Alcohol and Health From the Secretary of Health and Human Services. Washington, DC: USDHHS, Public Health Service, National Institutes of Health, National Institute on Alcohol Abuse and Alcoholism, 1997.

U.S. Department of Health and Human Services (USDHHS). Tenth Special Report to the U.S. Congress on Alcohol and Health: Highlights From the Current Research. Rockville, MD: USDHHS, Public Health Service, National Institutes of Health, National Institute on Alcohol Abuse and Alcoholism, 2000.

Veenstra, J.; Ockhuizen, T.; VAn de Pol, H.; ET AL. Effects of a moderate dose of alcohol on blood lipids and lipoproteins postprandially and in the fasting state. Alcohol 25:371-377, 1990.

Wannamethee, G., AND Shaper, A.G. Alcohol and sudden cardiac death. British Heart Journal 68:443-448, 1992.

World Health Organization (WHO). Manual of the International Statistical Classification of Diseases, Injuries and Causes of Death, Ninth Revision. Geneva: WHO, 1977.

World Health Organization (WHO). International Statistical Classification of Diseases and Related Health Problems, Tenth Revision. Tabular List. Geneva: WHO, 1992.

World Health Organization (WHO). International Classification of Functioning, Disability and Health. Geneva: WHO, 2001.

Willich, S.N.; LOWEL, H.; LEWIS, M.; ET AL. Weekly variation of acute myocardial infarction. Increased Monday risk in the working population. Circulation 90:87-93, 1994.

Wu, T., AND TREvisan, M. Drinking pattern and hypertension in a population-based sample. American Journal of Epidemiology 153:S59, 2001.

YAFFEE, R. Introduction to Time-Series Analysis and Forecasting. San Diego, CA: Academic Press, 2000.

ZADOR, P.L. Alcohol-related relative risk of fatal driver injuries in relation to driver age and sex. Journal of Studies on Alcohol 52:302-310, 1991.

ZAKHARI, S. Alcohol and the cardiovascular system: Molecular mechanisms for beneficial and harmful action. Alcohol Health \& Research World 21:21-29, 1997.

Zeegers, M.; Tan, F.; Verhagen, A.P.; et al. Elevated risk of cancer of the urinary tract for alcohol drinkers: A meta-analysis. Cancer Causes and Control 10(5):445-451, 1999.

Zwerling, C.; Sprince, N.; Wallace, R.; ET Al. Alcohol and occupational injuries among older workers. Accident Analysis and Prevention 28: 371-376, 1996. 